University of South Florida

DIGITAL COMMONS

Digital Commons @ University of

@ UNIVERSITY OF SOUTH FLORIDA

South Florida

8-1984

\title{
Instability Waves Observed on the Equator in the Atlantic Ocean during 1983
}

Robert H. Weisberg

North Carolina State University at Raleigh, weisberg@marine.usf.edu

Follow this and additional works at: https://digitalcommons.usf.edu/msc_facpub

\section{Scholar Commons Citation}

Weisberg, Robert H., "Instability Waves Observed on the Equator in the Atlantic Ocean during 1983" (1984). Marine Science Faculty Publications. 397.

https://digitalcommons.usf.edu/msc_facpub/397

This Article is brought to you for free and open access by the College of Marine Science at Digital Commons @ University of South Florida. It has been accepted for inclusion in Marine Science Faculty Publications by an authorized administrator of Digital Commons @ University of South Florida. For more information, please contact digitalcommons@usf.edu. 
Abstract. A packet of surface confined westward propagating waves apparently generated by barotropic instability of the surface currents was observed in the equatorial Atlantic during 1983. Initial wavenumber analyses and energetics calculations are presented. Local working by the horIzontal Reynolds stress was large enough and at the correct time to account for the wave packet's existence. The amplitude of the waves was comparable to the mean currents implying that the waves are of primary importance in the momentum balance of the seasonally varying equatorial surface currents.

\section{Introduction}

Large scale meanders of the surface South Equatorial Current (SEC) and the subsurface Equatorial Undercurrent (EUC) were first described by Düing et al. (1975) using measurements made in the equatorial Atlantic during July-Sept. 1974. Westward propagating oscillations with a periodicity of around 16 days were observed. Weisberg (1979) showed that these were confined primarily to the surface region. Using infrared satellite imagery, Legeckis (1977) pointed out similar surface features in the eastern equatorial Pacific Ocean and this analysis was expanded upon by Legeckis et al. (1983) to include data from 19751981. Summer and fall seasons showed westward propagating oscillations with a mean period and zonal wavelength of 25 days and $1000 \mathrm{~km}$ respectively. Halpern (personal communications) has observed similar seasonal behavior in moored current meter records from that region. Waves occurred when the equatorial surface currents were westward.

Deep expressions of these surface meanders have also been observed. Weisberg et al. (1979), using moored current meter data from below the thermocline in the eastern equatorial Atlantic Ocean, identified a packet of equatorially trapped Rossby-gravity waves with central periodlcity of 31 days and westward and upward phase propagation with length scales of $1200 \mathrm{~km}$ and $1000 \mathrm{~m}$ respectively. Further analyses by Weisberg and Horigan (1981) suggested that these waves were seasonal with their origin in the central equatorial Atlantic during July-Aug. Indications of oscillations with around 30 day periodicity in the deep equatorial Indian Ocean shown by Luyten and Roemmich (1982) further suggest that these features are universal to equatorial oceans.

Barotropic instability between the westward SEC and the eastward North Equatorial Countercurrent (NECC) appears to be the origin of the meanders. Analytical and numerical calculations by

Copyright 1984 by the American Geophysical Union.

Paper number 4L6110.

0094-8276/84/004L-6110\$03.00
Philander (1978) and Cox (1980) respectively show narrow band instabilities with both rapid growth rate and the observed scales. Waves are seasonally generated as the SEC and NECC intensify in response to seasonally varying wind stress.

During the first year of the SEQUAL experiment a packet of the above waves was observed in current meter records from five surface moorings: three along the equator near $28^{\circ} \mathrm{W}, 24^{\circ} \mathrm{W}$, and $15^{\circ} \mathrm{W}$, and two along $28^{\circ} \mathrm{W}$ near $45^{\prime} \mathrm{N}$ and $45^{\prime} \mathrm{S}$. Initial analyses of the wave packet are presented with emphasis on phase propagation and energy flux. Supporting data from surface ship observations are given by McPhaden et al. (1984).

\section{Data}

Table 1 lists mooring positions and instrument depths for Vector Averaging (VACM) and Vector Measuring (VMCM) current meters on surface moorings from Feb.-Sept. 1983. North components of velocity at the $10 \mathrm{~m}$ level from the three positions along $28^{\circ} \mathrm{W}$ and at the equator, $15^{\circ} \mathrm{W}$ are shown as examples in Figure 1. A wave packet appears around mid-May at $28^{\circ} \mathrm{W}$ and somewhat later at $15^{\circ} \mathrm{W}$. The packet exists over 2-3 cycles with a central periodicity of 25 days. Oscillations appear primarily in the north component (v) as opposed to the east component (u) or temperature and their amplitude diminishes rapidly with depth.

\section{Kinematics}

Frequency domain empirical orthogonal function analyses were performed about a central frequency of $4.0 \times 10^{-2}$ cpd as determined from spectral analyses of all time series. Cross-spectral matrices, each element computed with approximately 17 degrees of freedom as determined from record length and bandwidth, were constructed and their eigenvalues and eigenfunctions calculated. This was done horizontally for $v$ at each separate depth and vertically for both $v$ and $u$ at the equatorial $28^{\circ} \mathrm{W}$ mooring. The eigenvalues partition variance into orthogonal modes and the eigenfunctions give the spatial distribution of amplitude and phase for each mode.

First mode results for $v$ as a function of horizontal position at each depth are shown in Figure 2. With the exception of the $150 \mathrm{~m}$ leve1, the first mode contains $85 \%-90 \%$ of the variance within the band. Phase propagation is consistently westward with data points closely grouped about a mean zonal wavenumber component of $-5.5 \times 10^{-3} \mathrm{rad} / \mathrm{km}$ ( $1140 \mathrm{~km}$ wavelength) correspondIng to a phase speed of $-53 \mathrm{~cm} / \mathrm{sec}$. Motions are in phase meridionally along $28^{\circ} \mathrm{W}$ and the amplitudes are fairly uniform at each depth.

First mode results, including $84 \%$ and $55 \%$ of the variance of $v$ and $u$ respectively, are shown as a function of depth in Figure 3. The amp1itude of $v$ exceeds that of $u$ at all depths and it 
Table 1. Mooring positions and instrument depths for current meter records from Feb.Sept. 1983.

\begin{tabular}{rrrrrr}
\hline & $0^{\circ} 44^{\prime} \mathrm{N}$ & $0^{\circ} 00^{\prime} \mathrm{N}$ & $0^{\circ} 45^{\prime} \mathrm{S}$ & $0^{\circ} 03^{\prime} \mathrm{N}$ & $0^{\circ} 01^{\prime} \mathrm{S}$ \\
$28^{\circ} 11^{\prime} \mathrm{W}$ & $28^{\circ} 09^{\prime} \mathrm{W}$ & $28^{\circ} 10^{\prime} \mathrm{W}$ & $28^{\circ} 59^{\prime} \mathrm{W}$ & $14^{\circ} 57^{\prime} \mathrm{W}$ \\
\hline $10 \mathrm{~m}$ & VACM & VACM & VACM & & VMCM \\
$50 \mathrm{~m}$ & & VACM & & VACM & VACM \\
$75 \mathrm{~m}$ & VACM & VACM & VACM & VACM & VACM \\
$100 \mathrm{~m}$ & VACM & VACM & & & \\
$150 \mathrm{~m}$ & VACM & VACM & VACM & VMCM & VMCM \\
$200 \mathrm{~m}$ & & VACM & & & \\
\hline
\end{tabular}

decreases precipitously below $50 \mathrm{~m}$. Phase is fairly uniform for $v$ while it varies for $u$. This results in a nearly in phase relationship between $\mathrm{v}$ and $\mathrm{u}$ over the upper $50 \mathrm{~m} \mathrm{with}$ an attendant non-zero Reynolds stress versus a nearly $\pi / 2$ phase difference below 50 m suggesting that the Reynolds stress is zero below the surface layer.

\section{Energetics}

Contrary to the wavenumber analysis resulting in westward phase propagation, inspection of the data, e.g., Figure 1, suggests eastward energy flux. To assess this, the $v$ time series were

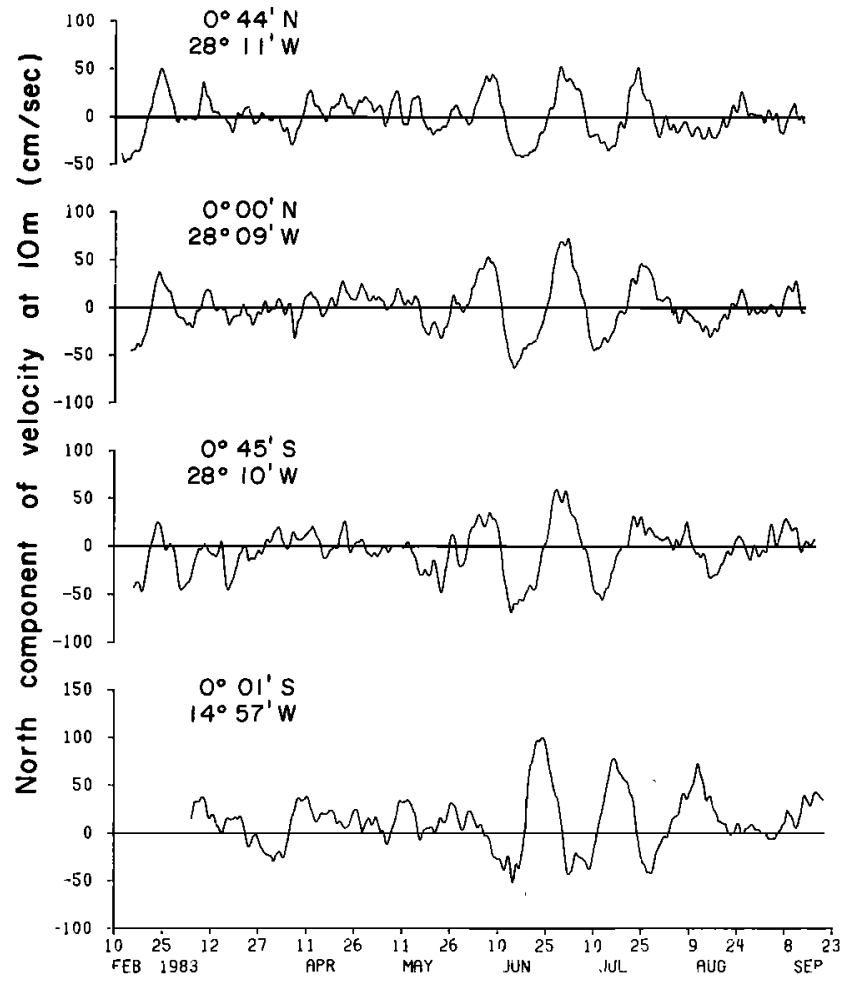

Fig. 1. Low pass filtered north component time series at a depth of $10 \mathrm{~m}$.
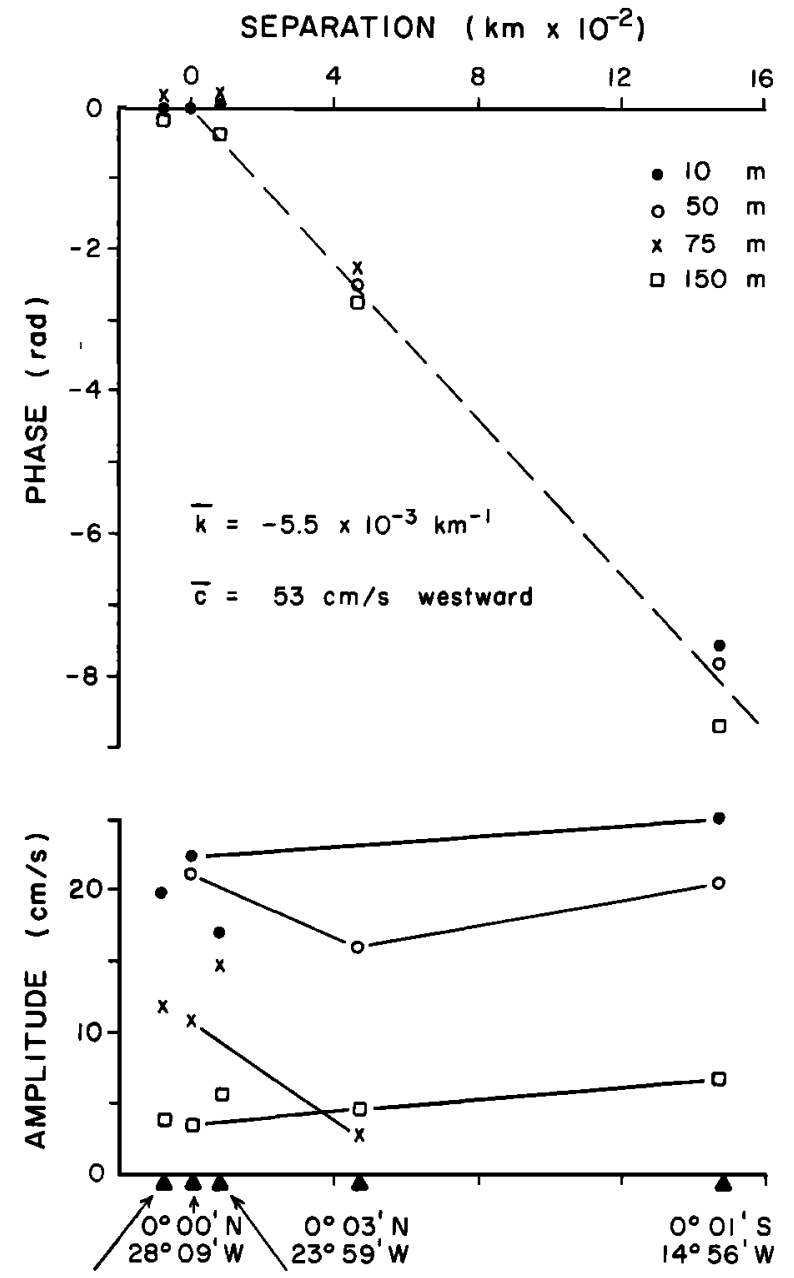

$0^{\circ} 46^{\prime} \mathrm{S} \quad 0^{\circ} 44^{\prime} \mathrm{N}$ $28^{\circ} 10^{\prime} W \quad 28^{\circ} 11^{\prime} W$

Fig. 2. Amplitude and phase of the first empirical orthogonal mode as a function of horizontal position computed for north components at each individual depth. Central frequency and bandwidth for the calculations are $4.0 \times 10^{-2} \mathrm{cpd}$ and $4.4 \times 10^{-2}$ cpd respectively.

complex demodulated about a 25 day periodicity using the same bandwidths as in the wavenumber analysis. The resulting envelopes for the wave packet are shown in Figure 4. The upper curves are from the $50 \mathrm{~m} \mathrm{level}$ at the three zonal positions along the equator. Eastward movement of the packet is clearly seen. The middle curves are from the $10 \mathrm{~m} \mathrm{level} \mathrm{at} \mathrm{the} \mathrm{three} \mathrm{meridional}$ positions along $28^{\circ} \mathrm{W}$. No meridional energy flux is observed. The lower curves are from the $10 \mathrm{~m}$, $50 \mathrm{~m}$, and $75 \mathrm{~m}$ depths on the equatorial $28^{\circ} \mathrm{W}$ mooring. Downward energy flux is evident.

The apparent zonal component of group velocity may be estimated from the lag times between different zonal positions along the equator. This is shown in Figure 5 using both cross-covariances and modal times at $10 \mathrm{~m}$ and $50 \mathrm{~m}$. A mean value of $124 \mathrm{~cm} / \mathrm{sec}$ is obtained. Similarly the apparent vertical component of group velocity is estimated at $-8.7 \times 10^{-3} \mathrm{~cm} / \mathrm{sec}$.

Whence does the wave packet derive its energy? If barotropic instability is the mechanism then 


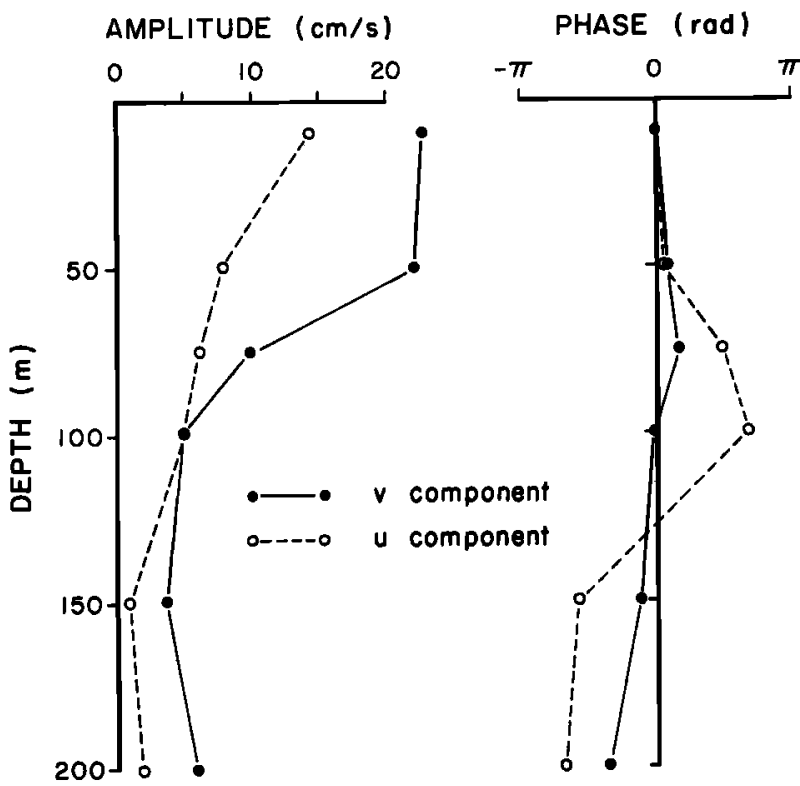

Fig. 3. Amplitude and phase of the first empirical orthogonal mode as a function of depth at $0^{\circ} 00^{\prime} \mathrm{N}, 28^{\circ} 09^{\prime} \mathrm{W}$ computed for north and east components. Central frequency and bandwidth for the calculations are $4.0 \times 10^{-2}$ cpd and $4.4 \times 10^{-2}$ cpd respectively.

the production term $-\overline{\rho u^{\prime} v^{\prime}} \partial U / \partial y$ is important, where $\overline{\rho u^{\prime} v^{\prime}}$ is the horizontal Reynolds stress and $\partial U / \partial y$ is the mean meridional shear of the zonal current system. Positive values of the production term indicate fluctuation energy derivation at the expense of the mean currents. Figure 6 shows Reynolds stress time serles at the equatorial $28^{\circ} \mathrm{W}$ mooring calculated as 25 day running means. Since $\partial \mathrm{U} / \partial \mathrm{y}$ was observed to be negative,

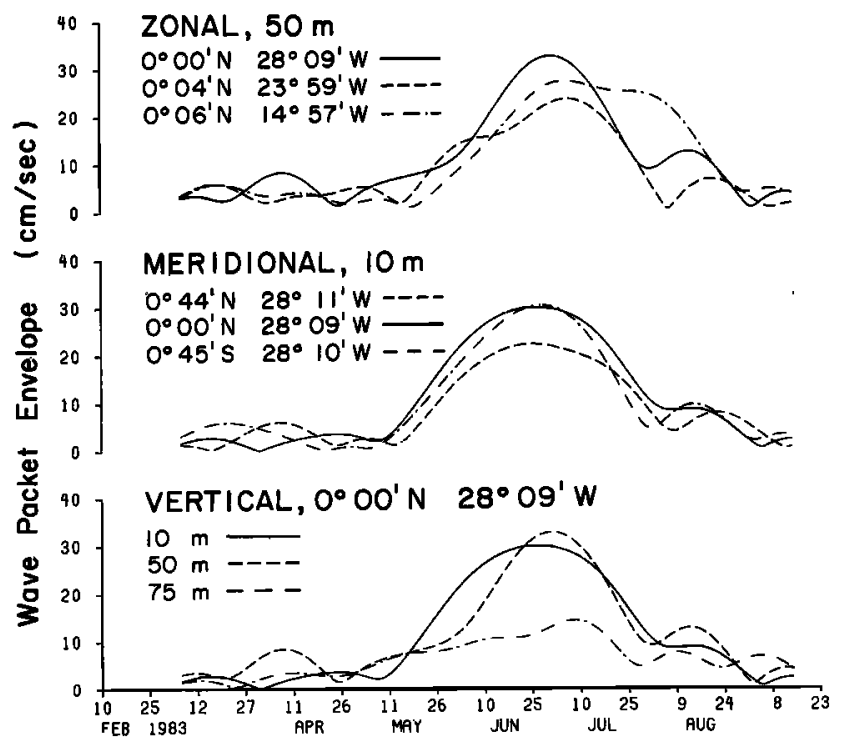

Fig. 4. Wave packet envelopes as a function of time at different zonal, meridional, and vertical positions calculated by complex demodulation about a central frequency of $4.0 \times 10^{-2} \mathrm{cpd}$ with a bandwidth of $4.4 \times 10^{-2} \mathrm{cpd}$.

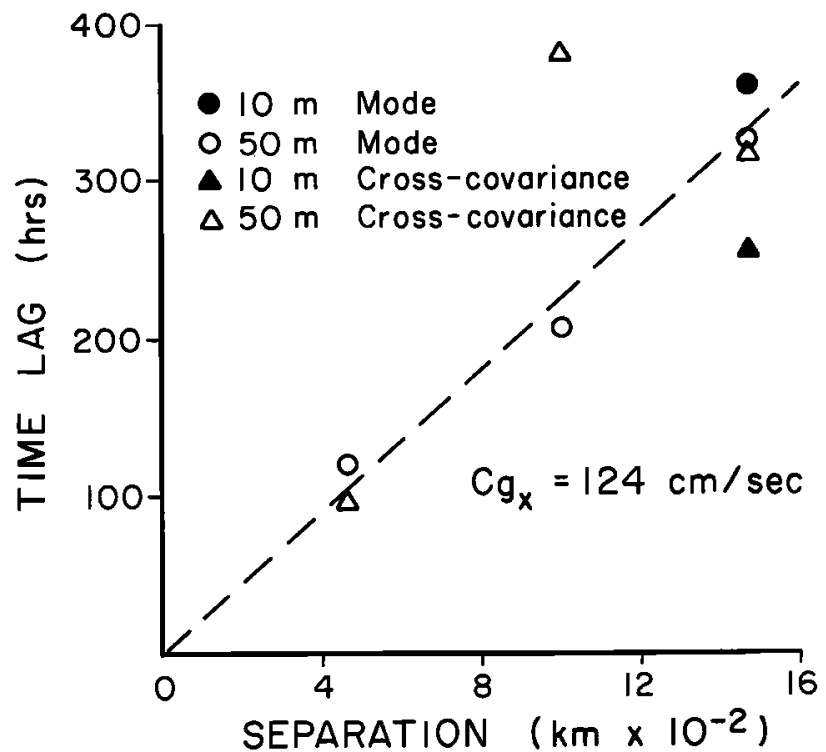

Fig. 5. Time lags for the wave packet envelopes as a function of zonal separation for north components at depths of $10 \mathrm{~m}$ and $50 \mathrm{~m}$. Lags were obtalned from both cross-covariances and modal times.

positive Reynolds stress is required for energy transfer from the mean currents to the waves. At the $10 \mathrm{~m}$ level the Reynolds stress is zero until the beginning of June. It is then positive for one month reaching a peak during mid-June. The timing of this Reynolds stress pulse matches the wave packet very closely with the Reynolds stress peak corresponding to the maximum rate of change of the packet envelope and the end of the pulse corresponding to the maximum packet amplitude. Integrating the Reynolds stress pulse times $\partial U / \partial y$ obtained between $45^{\prime} \mathrm{N}$ and the equator shows that local production is more than adequate to account for the kinetic energy of the wave packet. Below $50 \mathrm{~m}$ the Reynolds stress reduces to zero showing that most of the production is above the thermocline.

\section{Summary}

Part of the seasonal cycle in the equatorial oceans is the generation of waves with time scales of around 3 weeks and length scales of around $1000 \mathrm{~km}$. A packet of these waves was observed during the first year of the SEQUAL experiment lasting 2-3 cycles with central periodicity of 25 days and zonal wavelength of $1140 \mathrm{~km}$. Phase propagation was westward at around 53 $\mathrm{cm} / \mathrm{sec}$ while the packet envelope (apparent group velocity) progressed eastward and downward at around $124 \mathrm{~cm} / \mathrm{sec}$ and $8.7 \times 10^{-3} \mathrm{~cm} / \mathrm{sec}$ respective1y. No Indications of mefidional phase or energy propagation were evident and wave energy fell rapidly below $50 \mathrm{~m}$. Horizontal Reynolds stress time series along with the meridional shear of the zonal currents suggested that local wave energy production by barotropic instability was large enough and at the correct time to account for the' wave packet's existence. Reynolds stress time series were in phase meridionally and vertically but progressed eastward zonally. It is 


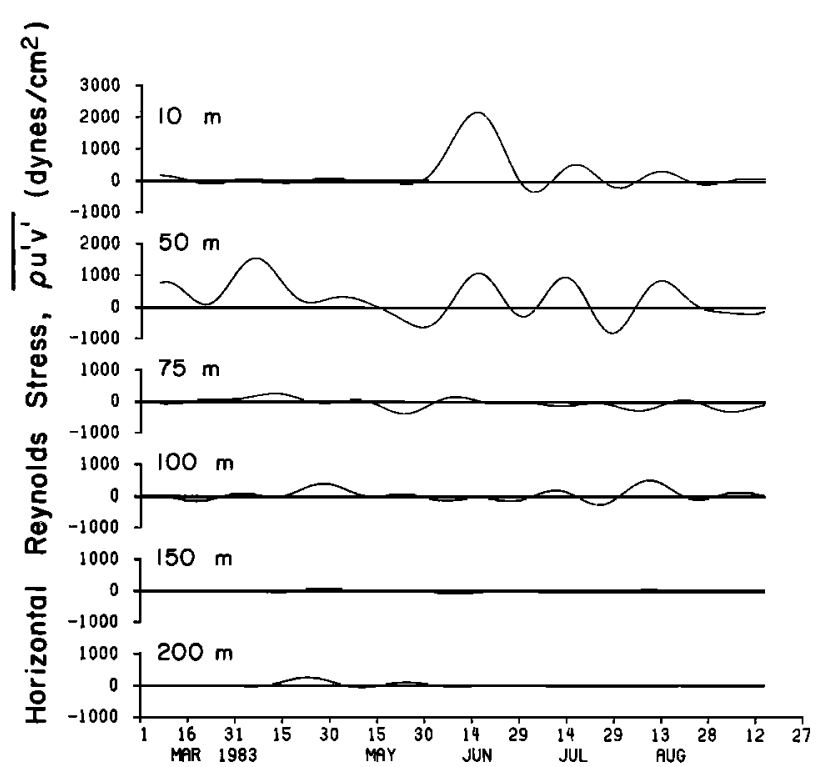

Fig. 6. Reynolds stress time series for all depths at $0^{\circ} 00^{\prime} \mathrm{N}, 28^{\circ} 09^{\prime} \mathrm{W}$ computed as a running mean over 25 days.

unclear whether the apparent eastward energy flux results from propagation or local generation by an eastward progressing instability. Analysis of the combined SEQUAL/FOCAL data sets along with numerical model experiments may aid in this interpretation. Since the amplitude of these waves at the ocean surface is comparable to the magnitude of the mean currents, the waves are of primary importance in the momentum balance of the seasonally varying equatorial surface currents.

It is also interesting to note that with a slight shift to lower frequency, the packet observed here is nearly identical in zonal wavelength, phase speed, packet dimension, and timing to the Rossby-gravity wave packet previously observed below the thermocline in the eastern equatorial Atlantic as mentioned in the introduction. The equatorial waveguide does serve as a conduit for some of the wave energy generated near the surface; just how much will be a topic of continued study.

Acknowledgements. Support was provided by the Oceanography Section, National Science Foundation, under Grant FOCE-8211848. Fleld work was performed aboard the $R / V$ Conrad and $R / V$ Knorr and the able assistance of their captains and crew are appreciated. Current meters were prepared by the Technical Services Group, Graduate School of
Oceanography, Untversity of R.I. and the Woods Hole Oceanographic Institute Buoy Group. P. Blankinship of the North Carolina State University was responsible for all of the mooring operations. J. Hickman and T. Clay assisted with computing and drafting and T.Y. Tang assisted with the analyses.

\section{References}

Cox, M.D., Generation and propagation of 30-day waves in a numerical model of the Pacific, J. Phys. Oceanogr., 10, 1168-1186, 1980.

Düing, W., P. Hisard, E. Katz, J. Knauss, J. Meincke, L. Miller, K. Moroshkin, G. Philander, A. Rybnikov, K. Voigt, and R. Weisberg, Meanders and long waves in the equatorial Atlantic, Nature, 257, 280-284, 1975.

Legeckis, R., Long waves in the eastern equatorial Pacific Ocean: A view from a geostationary satellite, Science, 197, 1179-1181, 1977.

Legeckis, R., W. P1che1, and G. Nesterczuk, Equatorfal long waves in geostationary satellite observations and multichannel sea surface temperature analysis, Bul1. Am. Met. Soc., 64, 133-139, 1983.

Luyten, J.R. and D.H. Roemm1ch, Equatorial currents at semi-annual period in the Indian Ocean, Jour. Phys. Oceanogr., 12, 406-413, 1982 .

McPhaden, M.J., M. Fieux, and J. Gonella, Meanders observed in surface currents and hydrography during an equatorial Atlantic transect, Geophys. Res. Lett., (this issue), 1984.

Philander, S.G.H., Instabilities of equatorial currents, Part II, J. Geophys. Res., 83, 3679-3682, 1978 .

Welsberg, R.H., Equatorial waves during GATE and their relation to the mean zonal circulation, Deep-Sea Res., 26, (Supp1. II), 179-198, 1979 .

Weisberg, R.H., A. Horigan, and C. Colin, Equatorially trapped Rossby-gravity wave propagation in the Gulf of Guinea, J. Mar. Res., 37, $67-86,1979$.

Weisberg, R.H. and A.M. Horigan, Low frequency variability in the equatorial Atlantic, Jour. Phys. Oceanogr., 11, 913-920, 1981 .

R.H. Weisberg, Department of Marine, Earth and Atmospheric Sciences, North Carolina State University, Raleigh, NC 27695.

(Received March 8, 1984; accepted Apri1 16, 1984.) 